\title{
Contribuições de Kant, Dewey e Deleuze para o ensino de Filosofia na educação básica
}

\section{Contributions of Kant, Dewey and Deleuze to teaching Philosophy in basic education}

\author{
Rafael Batista \\ Mestrando na Universidade Federal do Paraná, Curitiba, Paraná, Brasil. \\ rafaelbatistafilosofia@gmail.com
}

Recebido em 05 de junho de 2018

Aprovado em 17 de dezembro de 2018

Publicado em 23 de janeiro de 2019

RESUMO: O presente artigo tem por objetivo pesquisar as contribuições de Kant, Dewey e Deleuze para o ensino de filosofia na educação básica. Investiga o ensino de filosofia e sua contribuição para o desenvolvimento de um pensamento autônomo e que conecte a vida com os conceitos filosóficos. O procedimento adotado consiste numa pesquisa bibliográfica dos autores na tentativa de aproximá-los com uma discussão teórica sobre o ensino de filosofia. Foca-se, em Kant, no conceito e a finalidade da educação. Em Dewey analisa-se o entendimento de que a educação é um fenômeno direto da vida e intimamente ligado com as experiências da criança. Em Deleuze e Guattari explora-se a particularidade da filosofia no trato com o conceito e numa geografia do pensamento, na tentativa de analisar o trabalho de filosofia com conceitos, na educação básica, a partir da ideia de territórios. Desta forma, delineiam-se possibilidades de contribuição do ensino de filosofia na educação básica: o pensamento autônomo e a relação da vida com os conceitos filosóficos. Palavras-chave: Autonomia; Conceitos; Experiência; Vida.

\begin{abstract}
This article aims to investigate the contributions of Kant, Dewey and Deleuze to the teaching of philosophy in Basic Education. It investigates the possibility of teaching philosophy to contribute to the development of an autonomous thinking and that connects life with philosophical concepts. The procedure adopted consists of a bibliographical research of the authors in an attempt to approach them with a theoretical discussion about the teaching of philosophy. It focuses on Kant's concept and purpose of education. In Dewey the understanding is analyzed that education is a direct phenomenon of life and intimately connected with the experiences of the child. In Deleuze and Guattari, the peculiarity of philosophy is explored in dealing with the concept and in a geography of thought, in an attempt to analyze the work of philosophy with concepts, in basic education, from the idea of territories. In this way, possibilities of contribution of the teaching of philosophy in the basic education are developed: the autonomous thought and the relation of the life with the philosophical concepts. Keywords: Autonomy; Concepts; Experience; Life.
\end{abstract}




\section{Introdução}

A filosofia como componente curricular da educação básica vive uma situação desafiadora em nosso país; ela voltou, em 2008, após anos de discussões, congressos acadêmicos e pressões políticas, como componente curricular obrigatório no Ensino Médio. Passados apenas 10 anos, um novo cenário de instabilidade paira sobre sua presença na educação básica, agora instituída como a obrigatoriedade de 'estudos e práticas' no Ensino Médio, perdendo caracterização de componente curricular obrigatório. O cenário é incerto, pois a presença e os rumos do trabalho com filosofia no Ensino Médio ainda serão definidos, após a homologação da Base Nacional Comum Curricular (BNCC), pelas redes de ensino.

Pode-se observar que esta crise instaurada no ensino de filosofia no Brasil é um efeito de uma crise mundial que se materializa num projeto restritivo para a área das humanidades. Essa restrição se dá em nome de uma educação voltada para o crescimento econômico que desconsidera o papel inegável das humanidades para com a democracia. "Tanto no ensino fundamental e médio como no ensino superior, as humanidades e as artes estão sendo eliminadas em quase todos os países do mundo" (NUSSBAUM, 2015, p. ).

Diante desse cenário, intensifica-se a necessidade de compreender o papel da filosofia na educação básica e qual sua contribuição para a formação dos jovens e adolescentes. Comumente acredita-se que a filosofia ajude na emancipação do jovem estudante, construindo um sujeito com autonomia de pensamento. Papel este que não é exclusivo da filosofia, mas que é esperado da sua presença na educação básica. Associado a isso, há uma necessidade implícita, nesta etapa de ensino, de que ocorra uma conexão dos conteúdos específicos com a vida do estudante, de modo que os conceitos estudados façam sentido e ressignifiquem a experiência e a visão de mundo do jovem. O que se pretende é estabelecer uma fundamentação filosófica para pensar o ensino de filosofia alicerçado na autonomia do sujeito estudante.

Dado o presente contexto, este artigo discorre sobre a seguinte problemática: O ensino de filosofia na educação básica é capaz de promover a autonomia de pensamento e estabelecer conexões da vida com os conceitos filosóficos? Cabe salientar que este trabalho não se constitui num manifesto para a permanência da filosofia no ensino médio, nem tampouco tem a pretensão de delimitar, por exaustão, o papel da filosofia na formação do jovem estudante. O que se quer é traçar o entendimento das possibilidades de contribuição do ensino de filosofia para a formação na educação básica.

Estuda-se possibilidades de contribuição para a formação a partir dos seguintes aportes: Immanuel Kant (1999), John Dewey (1959), Gilles Deleuze e Félix Guattari (2010). De Kant estuda-se o conceito e a finalidade da educação, fazer com que a criança seja um sujeito autônomo e cidadão do mundo. De Dewey analisa-se o entendimento de que a educação é um fenômeno direto da vida e intimamente ligado com as experiências da criança. Em Deleuze e Guattari explora-se a particularidade da filosofia no trato com o conceito e numa geografia do pensamento, na tentativa de analisar o trabalho de filosofia com conceitos, na educação básica, a partir da ideia de territórios. As contribuições desses filósofos serão analisadas sob o ponto de vista de aproximá-las com o ensino de filosofia no ensino médio. Desta forma, pretende-se traçar algumas das possibilidades de contribuição da filosofia para com a educação básica. 


\section{Kant e o desenvolvimento da autonomia pela educação}

Para o entendimento das possibilidades de contribuição do ensino de filosofia, se faz necessária uma análise do pensamento de Kant sobre a educação, ideias que contribuíram para o estabelecimento da educação na sociedade moderna. Para isso, é feita uma análise da obra Sobre a pedagogia (1999), que possibilita o entendimento da educação como uma prática da liberdade, objetivando a autonomia das crianças.

A obra é organizada em três partes: uma introdução, em que é feita uma análise da disciplina desde a infância, visando um desenvolvimento para a maturidade, sendo necessária para a formação humana. A segunda parte trata 'Sobre a educação física', que aborda os cuidados com o corpo e a saúde. Por fim, a terceira parte 'Sobre a educação prática' dá contribuições voltadas para a moral e para a formação cultural, essenciais para uma convivência harmoniosa em sociedade.

A questão da educação permeia o pensamento de Kant, entendendo-a como "processo inicial do esclarecimento da razão, que culmina obrigando o homem a ver-se como humanidade" (PINHEIRO, 2007, p. 13). Para o filósofo, existem vários obstáculos no desenvolvimento do homem e da humanidade, fazendo com que a educação seja necessária, somente por ela o indivíduo torna-se plenamente responsável. "O homem não pode se tornar um verdadeiro homem senão pela educação. Ele é aquilo que a educação dele faz. Note-se que ele só pode receber a educação de outros homens, os quais a receberam igualmente de outros" (KANT, 1999, p.15).

Mas o que é o homem? É um duplo aspecto, entre um ser biológico e um ser racional, entre a natureza e a humanidade, sendo uma espécie de resultado produzido pela educação. Nesse sentido, a educação está relacionada com uma ideia de progresso, que carrega consigo um ideal de perfeição do homem e da humanidade, sem esquecer que se vive no mundo. Esse progresso seria como que impulsionado pelos obstáculos, dando início a reflexão. A partir disso ocorreria a passagem do homem para a humanidade.

Esse duplo aspecto que constitui o ser humano é expresso em dois âmbitos: o fenomênico e o numênico. "O primeiro é representado pela condição de cidadania do indivíduo na sociedade, e o segundo pela liberdade desse indivíduo, agora sujeito moral" (PINHEIRO, 2007, p. 38). O papel da educação diante dessa perspectiva é estabelecer a ligação possível entre esses dois âmbitos, dando sua contribuição para o progresso citado anteriormente. A educação busca as condições de uma possível passagem do homem à humanidade, visando o progresso em direção ao melhor, ela é a condição da capacidade de progresso. Vale lembrar que o homem é uma unidade, mas que só podemos observar cada face separadamente.

Percebe-se que a educação é um problema para o homem. Analisando o célebre texto kantiano Resposta à Pergunta "O que é Esclarecimento?" (Beantwortung der Frage: Was ist Aufklärung?) (1974) conclui-se que a saída da menoridade, necessária para o esclarecimento, depende da educação. Assim, remete-se a questão da possibilidade de passagem da sensibilidade ao entendimento, superando as adversidades impostas pela natureza e 
levando o homem a sua mais alta destinação, a ideia de humanidade. "Não cabe ao indivíduo a tarefa de conseguir atingir o fim supremo, mas à humanidade" (PINHEIRO, 2007, p. 61).

Acima foi dito que a educação em Kant se daria numa prática da liberdade, mas de que forma? Como ensinar a liberdade? Ela deve ser pensada sempre visando a humanidade. A humanidade em Kant seria no campo de uma natureza racional, deixando claro que não está relacionado a uma natureza humana, mas sim a racionalidade que faz com que o homem dê um princípio de ação e seja levado a agir a partir de tal princípio.

Kant nos ensina, na Crítica da razão pura, que o objeto desejado, quer seja todo o fenômeno, ou a prova da liberdade, é inacessível ao indivíduo, por ele não ser objeto do conhecimento, mas, quando muito, de fé. Ora, a dificuldade sobre a questão da possibilidade de ensinar liberdade vai além dos limites do individualismo. Apenas quando se leva em conta a humanidade é possível pensar nas condições de possibilidade de ensino da liberdade (PINHEIRO, 2007, p. 72).

Pode-se perceber que a educação visa a humanidade e o estabelecimento de uma racionalidade que faça com que os seres humanos sejam levados a agir, considerando a meta final da espécie, que em Kant seria a realização de uma constituição política perfeita. Neste sentido, política e educação são indissociáveis.

Até agora se analisou um entendimento sobre o processo de educação em Kant. Isso seria a pedagogia? Em que situação fica a filosofia perante essa problemática? O filósofo entende que a educação se constitui num processo filosófico e a pedagogia se caracteriza como uma ciência da educação. Então a educação ocupa-se de fundamentar o que é o homem e qual sua tarefa no mundo, enquanto a pedagogia deve fazer com que essa destinação seja efetivada.

No âmbito desse artigo, deve-se pensar em alternativas para que a filosofia no ensino básico cumpra com essa destinação, que é a promoção da autonomia do pensamento. Um dos possíveis caminhos para a realização desse projeto é o entendimento do que Kant propõe: a substituição do método catequético pelo método maiêutico socrático para a educação do julgamento. O método socrático se daria através da apresentação de uma série de problemas e a partir desses fazer com que os estudantes efetuem um julgamento, diferindo de um método mecânico de ensino. Através do método socrático o ser humano pode atingir o uso pleno da razão, em termos kantianos.

Desta forma, a tarefa fundamental da educação é dar mecanismos para que o homem se torne moral, isso só ocorrerá se ele puder pensar por si mesmo, sendo autônomo, capaz de se dar leis, que possam ser universais. Neste ponto que a filosofia na educação básica se faz necessária e pode auxiliar no desenvolvimento de um pensamento autônomo. Nas conclusões do texto abordar-se-á, na interface com os demais autores, uma possibilidade do ensino de filosofia na educação básica como o desenvolvimento da autonomia do pensamento. 


\section{Dewey e a educação para a vida}

O pensamento de John Dewey dialoga com o pensamento kantiano, no sentindo de que a educação contribui para o desenvolvimento da sociedade. A análise de seu pensamento para a educação se dá a partir das obras Vida e educação (1978), Como pensamos (1959) e Democracia e educação (1959). Pretende-se analisar a problemática da pesquisa agregando a análise de Dewey do papel da experiência e da vida para a educação, juntamente com o desenvolvimento da autonomia proposto por Kant.

Pode-se abordar a educação em Dewey como uma reconstrução da experiência. A experiência pode ser definida como uma ação sobre outro corpo e sofrer dele uma reação. Nesse sentido a experiência não é exclusividade humana. Delimitando para o campo humano, esse agir e reagir não fica preso somente ao plano biológico, mas perpassa à reflexão, o conhecimento e uma reconstrução da experiência. Assim, experiência pode ser definida como "a relação que se processa entre dois elementos do cosmos, alterando-lhes, até certo ponto, a realidade" (TEIXEIRA, 1978, p. 14).

O pensador entende que a vida, a experiência e a aprendizagem não podem se separar, pois são processos simultâneos e imbricados na educação. Mas o que seria educação? "Processo de reconstrução e reorganização da experiência, pelo qual lhe percebemos mais agudamente o sentido, e com isso nos habilitamos a melhor dirigir o curso de nossas experiências futuras" (TEIXEIRA, 1978, p. 17). Desta forma, a educação está intrinsicamente ligada à vida, sendo um fenômeno direto dela. No momento em que o ser humano reflete e reorganiza a experiência, Ihe é possibilitado um conhecimento para ele oriente suas experiências futuras. Assim, o fim da educação se identifica com seus meios, seria semelhante a dizer que a educação é resultado e processo de forma simultânea.

Entender o processo educativo em Dewey é conceber o indivíduo como um ser social; a educação deve libertar o indivíduo das forças e impulsos existentes, libertação que pode ocorrer na forma de direção desses impulsos. Nisso se pode pensar o papel da escola, que para Dewey não deve ser um lugar de preparação isolada, mas uma situação real de vida, em que indivíduo e sociedade se inter-relacionem.

Todo o pensamento de Dewey sobre a educação fundamenta-se numa premissa democrática, em que as sociedades não busquem somente a preservação dos seus costumes, mas uma renovação e revisão. O que se tem é a possibilidade de pensar a educação relacionada a uma experiência de vida, no sentido de que o processo educativo possa ressignificar a vida do estudante. "O pensamento faz-nos capazes de dirigir nossas atividades com previsão e de planejar de acordo com fins em vista ou propósitos de que somos conscientes" (DEWEY, 1959, p. 26).

A relação do autor com a problemática desse artigo se dá no entendimento de uma educação ligada à vida. Sendo assim, a filosofia na educação básica pode ser pensada através do estabelecimento de uma relação dos conceitos filosóficos com a vida do estudante, possibilitando entendimento de alguns aspectos de sua experiência anterior e possibilitando orientar as futuras. 


\title{
Deleuze e a reterritorialização do conceito
}

Para pensar alternativas de como o trabalho com filosofia no ensino básico pode ser realizado, foi escolhido Gilles Deleuze e Félix Guattari no entendimento que os mesmos têm da filosofia enquanto "arte de formar, de inventar, de fabricar conceitos" (DELEUZE, GUATARRI, 2010, p. 8). Contudo, há de se tomar cuidado para não cair na ingenuidade de pensar que, a partir do contato com a filosofia no ensino médio, os adolescentes irão possuir habilidades para a criação de conceitos no sentido deleuziano.

É importante ressaltar que o entendimento do processo filosófico em Deleuze dá-se de forma diferente dos filósofos analisados anteriormente. Para ele, fazer filosofia é muito mais do que repetir ou repensar o que os filósofos disseram, sem querer aqui dizer que os outros filósofos abordados só repetem ou repensam os demais.

\begin{abstract}
Quando Deleuze diz que o filósofo é criador e não reflexivo, o que pretende é se insurgir contra a caracterização da filosofia como metadiscurso, metalinguagem, uma tendência da filosofia moderna que, desde Kant, tem por objetivo formular ou explicitar critérios de legitimidade ou de justificação. Insurgindo-se contra essa tendência, ele reivindica para a filosofia a produção de conhecimento, ou, mais propriamente, a criação de pensamento. (MACHADO, 2009, p. 12)
\end{abstract}

Mas para Deleuze o que é um conceito? "O conceito é uma heterogênese, isto é, uma ordenação de seus componentes por zonas de vizinhança" (DELEUZE, GUATARRI, 2010, p. 28), que organizam campos de solução para problemas. Pode-se pensar a filosofia de Deleuze como um sistema de relações entre elementos heterogêneos. Como são criados os conceitos de sua filosofia?

Em primeiro lugar, há conceitos oriundos ou extraídos da própria filosofia, mais precisamente de alguns filósofos por ele privilegiados. [...] Em segundo lugar, há conceitos suscitados ou sugeridos pela relação entre conceitos filosóficos e elementos não conceituais provenientes de domínios exteriores à filosofia: por exemplo o que faz Proust com meios cinematográficos [...] serão importantes para a filosofia deleuziana. (MACHADO, 2009, p. 18)

A filosofia é precisamente o lugar dos conceitos, então pensar o que é externo a filosofia é uma forma de estabelecer encontros, conexões e articulações, que, quando são integrados a filosofia, tornam-se conceitos. Interessante observar esse ponto para o trabalho com filosofia no ensino médio, visto que se pode fazer um trabalho de articulação da filosofia com o que é externo a ela.

Dada a caracterização da filosofia em Deleuze, cabe abordar como que o trabalho com filosofia na educação básica pode ser realizado a partir do entendimento da filosofia 
como criação de conceitos. "Nunca se aprende fazendo como alguém, mas fazendo com alguém, que não tem relação de semelhança com o que se aprende" (DELEUZE, 2003, p. 21). Como foi dito anteriormente, há uma preocupação para que não se entenda a aula de filosofia, nesta etapa, como uma criação de conceitos no sentido deleuziano, pois sabe-se de todas as dificuldades de manejo conceitual desses estudantes. Assim, é feito um recorte que possibilita um entendimento de como os estudantes possam trabaIhar com os conceitos e ressignificá-los. Esse trabalho conceitual, no Ensino Médio, pode ser entendido através a dinâmica do movimento do pensamento; saindo de um território (desterritorialização) e indo em direção a um outro território (reterritorialização).

A partir desse entendimento, este artigo quer pensar o ensino de filosofia no ensino médio a partir da análise de conceitos. O território seria o campo conceitual já estabelecido, por exemplo o conceito de justiça em John Rawls, esse conceito já está criado e devidamente estabelecido na filosofia, pertencendo a um território. Quando se aborda esse conceito em sala de aula e se está pensando sobre ele, esse é o processo de desterritorialização, um processo de entendimento do que já está dado e criado num plano diferente, colocando-o sobre um outro território. Mas esse processo é inseparável da reterritorialização, que é a abertura a novos horizontes, ressignificando esse conceito para a realidade do aluno. Esse processo poderia ser exemplificado pelo entendimento do que o conceito de justiça de John Rawls pode lhe dizer sobre a atualidade, como o estudante pode entender a sua realidade a partir desse conceito. Percebe-se o cuidado para afastar a ideia de que o estudante da educação básica cria conceitos efetivamente, o que se propõe é o entendimento dos conceitos já estabelecidos e uma relação desses com a atualidade, na intenção de ressignificar o hoje.

Pode-se observar uma apropriação de aspectos da filosofia de Deleuze e Guatarri para se pensar o ensino da própria filosofia, os autores em questão não tinham como problema central o ensino de filosofia, mas é possível relacionar os aspectos de suas teorias com a problemática do ensino.

\section{Considerações Finais}

Por mais que Kant, Dewey, Deleuze e Guatarri pertençam a épocas e regiões bem diferentes, este artigo promove uma espécie de relação das contribuições de suas filosofias para com a educação e, especialmente, para o ensino de filosofia.

Pode-se dizer que há fortes evidências para fundamentar a contribuição da filosofia para a autonomia do pensamento na educação básica. Verifica-se a partir da fundamentação em Kant, de uma educação que contribua para o ideal de humanidade. Essa vocação da filosofia pode se dar ao apresentar e discutir com os estudantes temas importantes para que eles se compreendam como parte da humanidade.

Mas como a filosofia na educação básica pode auxiliar nessa tarefa? Pode-se responder a essa questão a partir de Dewey, no entendimento de uma educação atrelada a vida do 
estudante e que ressignifique a sua experiência. Surge a possibilidade de o ensino de filosofia na educação básica proporcionar uma ressignificação da experiência do estudante.

Quanto ao trato pedagógico próprio da filosofia e seu ensino na educação básica, sugere-se o entendimento de reterritorialização, sendo um processo em que o estudante ressignifique os conceitos estabelecidos na tradição filosófica numa relação com seu contexto.

Relacionando os três autores e aproximando-os de uma discussão sobre o ensino de filosofia, pode-se pensar em práticas que evidenciem as contribuições da autonomia de pensamento e conceitos relacionados com a vida do estudante. Essas práticas podem ser sobre quaisquer eixos estruturantes a filosofia no ensino médio. A proposta é que o professor pense em práticas que dialoguem com esses referenciais teóricos e apresentem uma série de problemas para que o estudante faça um julgamento; sempre ligados a uma situação real da vida através do trabalho conceitual na ideia de reterritorialização dos conceitos.

Diante de um momento de instabilidade da presença da filosofia no currículo da Educação Básica, torna-se urgente saber quais as suas contribuições e qual o espaço da experiência filosófica na formação do estudante.

Desta forma, esse artigo estabelece uma proposta para o ensino de filosofia que dialogue com Kant, Dewey, Deleuze e Guatatti no sentido de pensar a filosofia e seu ensino através do desenvolvimento da autonomia de pensamento e estabelecendo conexões da vida com os conceitos filosóficos. Possibilita um diálogo de aspectos conceituais dos autores para que a prática filosófica no Ensino Médio possa ser pensada a partir desse referencial.

\section{Referências}

DELEUZE, Gilles. Proust e os signos. 2a ed. Rio de Janeiro: Forense Universitária, 2003.

DELEUZE, Gilles; GUATARRI, Félix. Mil Platôs: Capitalismo e esquizofrenia. São Paulo: Editora 34, 1997.

DELEUZE, Gilles; GUATARRI, Félix. O que é a filosofia? 3. ed. São Paulo: Editora 34, 2010.

DEWEY, John. Como pensamos. 3. ed. São Paulo: Companhia Editora Nacional, 1959.

DEWEY, John. Democracia e educação. 3. ed. São Paulo: Companhia Editora Nacional, 1959.

DEWEY, John. Vida e educação. 10. ed. Rio de Janeiro: Melhoramentos, 1978.

PINHEIRO, Celso de Moraes. Kant e a educação. Caxias do Sul: Educs, 2007.

KANT, Immanuel. Resposta à Pergunta: 'O Que é Esclarecimento?'. Petrópolis: Vozes, 1974. Tradução de: Floriano de Souza Fernandes.

KANT, Immanuel. Sobre a pedagogia. 2. ed. Piracicaba: Unimep, 1999. 
MACHADO, Roberto. Deleuze e a filosofia. Rio de Janeiro: Graal, 1990.

MACHADO, Roberto. Deleuze, a arte e a filosofia. Rio de Janeiro: Jorge Zahar, 2009.

NUSSBAUM, Martha. Sem fins lucrativos: Por que a democracia precisa das humanidades. São Paulo: Martins Fontes, 2015.

TEIXEIRA, Anísio. A pedagogia de Dewey. In: DEWEY, John. Vida e educação. 10. ed. Rio de Janeiro: Melhoramentos, 1978. p. 13-41.

\section{(c) () (O)}

This work is licensed under a Creative Commons Attribution-NonCommercial 4.0 International (CC BY-NC 4.0) 